\title{
Interpretando o artefato: uma proposta metodológica de análise semiótica aplicada ao Design
}

Interpreting the artifact: a methodological proposal of a semiotic analysis applied to Design

SOUSA, Gustavo Augusto Lima de; Bacharel em Design; Universidade Federal do Rio Grande do Norte

gustavoyup@hotmail.com

BASTOS, Helena Rugai; Doutora; Universidade Federal do Rio Grande do Norte

helenarugai@gmail.com

\section{Resumo}

O presente artigo tem como objetivo a apresentação de um método de análise semiótico, que busca oferecer procedimentos para a interpretação de significados de artefatos, sempre levando em conta os contextos e as circunstâncias de produção dos mesmos. Para a construção desse método, o aporte teórico tem como base, principalmente, as pesquisas dos semioticistas Roland Barthes (2009; 2012; 2013) e Umberto Eco (1981; 2014; 2016), em especial suas obras dedicadas ao estudo da cultura material. Após a explicação das etapas de análise e dos conceitos semióticos que fundamentam o estudo, um exemplo de aplicação é apresentado, utilizando-se do artefato The Well-Tempered Chair (1986) do designer Ron Arad. Ao final, observa-se que o método proposto pode contribuir na elucidação de como os significados de artefatos são construídos, e, por esse motivo, vem sendo aplicado e aperfeiçoado em sala de aula, mostrando-se um recurso útil na reflexão sobre a criação das mensagens no campo do Design.

Palavras Chave: Design; linguagem; Semiótica.

\begin{abstract}
This paper aims to present a semiotic analysis method, which seeks to offer procedures for the interpretation of artifact meanings, always taking into account the contexts and circumstances of production. To build this method, the theoretical background is mainly based on the research of the semioticians Roland Barthes (2009; 2012; 2013) and Umberto Eco (1981; 2014; 2016), specially their works dedicated to the study of the material culture. After the explanation of the analysis steps and the essential semiotic concepts related to it, an example of an application is given, using the artifact The Well-Tempered Chair (1986) by the designer Ron Arad. At last, it is possible to observe that the proposed method can contribute to elucidate how the meanings of artifacts are built, and, for that reason, it has been applied and improved in the classroom, proving to be a useful resource in the debate about the way messages are created within Design.
\end{abstract}

Keywords: Design; language; Semiotics. 


\section{Introdução}

A partir do início do século XX, tornou-se cada vez mais comum a discussão sobre o poder comunicativo presente nos artefatos concebidos por designers. Seja a evocação de sentimentos, de funções práticas ${ }^{1}$ ou mesmo de ideias abstratas, todos esses aspectos são comumente estudados no Design ${ }^{2}$ sob o prisma da comunicação e, sobretudo, dos estudos da linguagem. ${ }^{3}$

Uma vez que todo processo comunicativo é um ato de produção de sentido e significação, existe aí o pressuposto de uma linguagem base, tornando assim esses dois conceitos, comunicação e linguagem, inseparáveis (GREIMAS \& COURTÉS, 2016, p. 80). Por esse motivo, para uma investigação do potencial comunicativo dos artefatos, é necessário considerar o estudo do Design como linguagem, levando em consideração suas idiossincrasias.

A Semiótica ${ }^{4}$, área por excelência do estudo das mais diferentes linguagens, tornou-se importante aliada na condução de uma reflexão epistemológica sobre o Design. ${ }^{5}$ Ela é capaz de oferecer uma série de conceitos operacionais, que auxiliam a examinar as mensagens construídas pela linguagem do Design. Nesse caminho, o estudo de uma linguagem é indissociável da observação das mensagens produzidas e, principalmente, o modo como essas mensagens são formuladas de maneira que sejam dotadas de significado.

Se, então, para estudar a linguagem do Design é preciso primeiro esmiuçar como essas mensagens são produzidas do ponto de vista da significação, é necessário um método de análise que contemple esses requerimentos. Este artigo apresenta resultado parcial de pesquisa maior sobre a concepção de artefatos, compreendidos como mensagens, e a construção de significados à luz da linguagem do Design. $O$ artigo tem como objetivo a apresentação de uma proposta de método de análise semiótica, que torne possível o estudo da linguagem que está inculcada nos artefatos e que os dota de poder significativo, permeando as mais diferentes manifestações do Design.

Para a construção desse método, dentre os diversos autores da Semiótica, a principal fonte de consulta nesta pesquisa foram os trabalhos de dois importantes semioticistas que se debruçaram diretamente sobre a aplicação de conceitos semióticos em análises de produtos da cultura material, a saber: Roland Barthes (2009; 2012; 2013) e Umberto Eco (1981; 2014; 2016).

Embora o recorte teórico tenha se dado ao redor dos autores mencionados, o procedimento de análise exposto aqui não busca rivalizar e, logo, excluir, a possível concatenação, durante a análise, de conceitos provenientes de linhas semióticas distintas. Na verdade, o método apresentado neste artigo deve ser compreendido como parte de uma pesquisa maior (SOUSA,

\footnotetext{
${ }^{1}$ Por funções práticas, refere-se neste artigo, principalmente, o uso principal e específico do artefato (funções de uso) e suas funções operacionais.

2 Destaca-se a área em que se desenvolve as atividades de design e o campo de conhecimento com a grafia em maiúscula e minúscula [Design] do processo de concepção ou o produto da prática profissional [design].

${ }^{3}$ A esse respeito, é bastante conhecido o panorama apresentado por Bürdek (2005), no qual o autor lista uma série de estudiosos das áreas da Semiótica e da Hermenêutica, relacionando suas pesquisas com o Design.

${ }^{4}$ Ao se referir ao campo do conhecimento, o termo 'semiótica' é grafado com inicial maiúscula [Semiótica] e sua forma adjetiva, indicando um tipo de abordagem (como em 'análise semiótica'), com inicial minúscula [semiótica].

${ }^{5}$ Assim, não é de surpreender a proliferação de trabalhos que tratam da relação entre Design e Semiótica. Da variada produção de pesquisas brasileiras nesse segmento, é possível citar alguns nomes como Vera Nojima e Frederico Braida (2014a; 2014b), Lucy Niemeyer (2007), Faria e Queiroz (2017), Lucréssia D’Alessio Ferrara (2002) e Lucia Santaella (2012).
} 
2017), que realizou investigação aprofundada na área de Semiótica, relacionando termos de diferentes procedências, principalmente a partir das interpretações de Eco (2014; 2016), na medida de sua possível coerência e contribuição para uma abordagem semiótica do Design. Portanto, deseja-se com esse artigo compartilhar os resultados dessa pesquisa realizada, que vem sendo aplicada em sala de aula.

Visando a melhor compreensão do método a ser apresentado, os primeiros tópicos deste artigo se dedicam ao esclarecimento de alguns conceitos chave no desenvolvimento da análise. Em seguida, o método em si é apresentado, conjuntamente com uma ilustração de aplicação, numa análise do artefato The Well-Tempered Chair (1986) do designer Ron Arad.

\section{O liame básico dos signos: o código}

Na Semiótica, considera-se usualmente o signo como a entidade elementar de estudo dessa área, uma vez que as linguagens se edificam em sistemas de signos (SOUSA, 2017, p. 21-22). Entretanto, Eco $(2014 ; 2016)$ afirma existir ainda uma outra unidade básica, que está pressuposta no signo, e que é essencial para os processos de significação: o código.

Recuperando o termo da Teoria da Informação e aplicando-o à sua teoria semiótica, Eco (2014) define o código como uma regra convencional, que associa elementos de um sistema sintático a elementos de um sistema semântico, isto é, relaciona "elementos de um sistema veiculante aos elementos de um sistema veiculado, o primeiro torna a expressão do segundo, o qual, por seu turno, torna-se o conteúdo do primeiro" (p.37). ${ }^{6}$

Desse modo, dada a sua arbitrariedade ${ }^{7}$, o código é um construto cultural, ou seja, instituído mediante convenção adotada por um grupo, determinando que, para dada expressão sensível, há um conteúdo inteligível. Se o código está intimamente conectado a uma cultura, sendo ao mesmo tempo seu produto e a base para as trocas de mensagem que ali ocorrem, devese considerá-lo suscetível a mudanças (crises) ao longo do tempo e, igualmente, variável entre culturas.

É o código o responsável pela conexão entre tudo aquilo que se chama de significante em um signo, isto é, a sua dimensão sensível, com aquele significado a que se atribui esse significante. Numa análise semiótica, procurar reconstituir os códigos, que direcionaram a construção da mensagem, é tentar compreender como os significantes, arranjados de um dado modo e lidos por um sujeito inserido num espaço-tempo, são capazes de veicular determinados significados.

Por esse motivo, o aprofundamento, ou até mesmo a precisão, de uma análise semiótica passa pelo repertório do analista. Se o intérprete da mensagem desconhece os códigos que foram

\footnotetext{
${ }^{6}$ O termo 'código', na Semiótica e na Linguística, pode também ser usado para designar as relações puramente sintáticas entre termos, isto é, as regras de organização dos signos na composição de uma mensagem coerente (e não a relação entre plano de expressão e plano de conteúdo, como Umberto Eco utiliza). Muitas vezes, é nessa acepção que se refere, por exemplo, a uma língua como código. É também nesses termos, que no par jakobsoniano código/mensagem (JAKOBSON, 2010), o código é compreendido: uma regra que torna previsível a criação de certas formas de mensagem.

${ }^{7}$ Vários autores irão argumentar diferentes pontos de vista sobre a arbitrariedade dos signos. Se, por um lado, os signos considerados como símbolos são unanimemente vistos como arbitrários e, logo, imotivados, o mesmo não ocorre com os signos icônicos e indiciais. Umberto Eco, por exemplo, foi um dos autores que rejeitou a aparente motivação entre o significante de um signo icônico e o seu referente, realizando uma "crítica ao iconismo" (ECO, 2014, p. 169).
} 
utilizados na construção daquele texto ${ }^{8}$, dificilmente ocorre a apreensão dos possíveis significados intencionados pelo destinador da mensagem.

No que tange a análise de artefatos, a pesquisa e o reconhecimento de códigos é a possibilidade de se identificar a que significados culturalmente estabelecidos em dado período do tempo, os significantes observados, como uma determinada cor, forma, cheiro, som ou até mesmo sabor, estão querendo comunicar naquele artefato. Portanto, ao tentar acompanhar o percurso do sentido, o código é uma espécie de ponte fundamental entre significante e significado, uma chave interpretativa. ${ }^{9}$ Mesmo que o conceito de código seja indispensável no método aqui apresentado, é necessária, ainda, uma explanação desses dois conceitos semióticos básicos, o significante e o significado, aplicados ao campo do Design, para melhor desenvolvimento das análises.

\section{Conceitos semióticos elementares numa abordagem semiótica do Design}

Por vezes, a Semiótica soa como uma área hermética em razão da idiossincrasia dos seus termos e, principalmente, das diferenças terminológicas sutis entre autores. ${ }^{10}$ Neste artigo, respeitando o alinhamento aos semioticistas estudados, utiliza-se a nomenclatura de significante, significado e referente para as entidades da tripartição do signo (ECO, 1981; 2014; e BARTHES, 2009; 2012). Para compreender como esses conceitos são úteis na análise de artefatos, este tópico se dedica à explanação de alguns vocábulos típicos da Semiótica aplicados ao Design.

\subsection{O significante}

O significante diz respeito à faceta sensível de um signo, aquela que ao ser percebida pelos sentidos, é compreendida por um sujeito como participante de uma função sígnica, ou seja, que está em relação com um significado a ser veiculado. Desse modo, no Design, considera-se como um significante tudo aquilo que é percebido em um artefato. Os exemplos mais comuns são materiais (incluído aí questões de peso, flexibilidade, textura, entre outros aspectos), formas, cores, palavras inscritas, tamanho, ajuste (em especial para vestimentas), sabores, odores, alertas sonoros. Enfim, a lista continua por quanto mais se deseje segmentar o artefato em partes que podem entrar em contato com um dos cinco sentidos.

Deve-se atentar para o fato de que, do ponto de vista da análise, o artefato em si, em sua totalidade, pode ser considerado como um único significante (um tipo de "forma total"), assim como suas partes constitutivas, outrossim, podem ser tomadas individualmente como significantes. Nesse caminho, é possível falar de um significante total e de significantes constitutivos do artefato. Ao analisar um artefato, parte-se do pressuposto que a conjunção dos significantes constitutivos não é arbitrária, e que o seu conjunto compõe uma unidade significativa planejada pelo designer, sendo cada significante e o significado a que ele reporta organizados

\footnotetext{
${ }^{8}$ Termo 'texto' utilizado neste artigo em acepção abrangente, como toda malha de signos (verbais ou não) organizada de modo coerente, uma unidade de sentido, e não necessariamente o texto verbal.

${ }^{9}$ Como observa Eco (2014), nem sempre o sujeito tem o código que permite interpretar dada mensagem tal como foi intencionada. Nesses casos, ocorre o chamado fenômeno de hipocodificação, em que suposições realizam a ligação entre significante e significado, muitas vezes criando conexões inéditas, como é o caso, descrito pelo autor (ECO, 2016, p. 200) dos camponeses que desconheciam o vaso sanitário.

${ }^{10}$ Essa extenuante variabilidade pode ser observada, por exemplo, no estudo que Eco faz em seu livro O signo (1981, p. 25).
} 
daquele modo em razão de um intento comunicativo. ${ }^{11}$

Quanto à pertinência de determinados significantes na leitura da mensagem comunicada, a determinação do que é ou não pertinente passa pelo conhecimento ou não do código que relaciona o significante total ao seu significado ${ }^{12}$. É possível explicar: reconhecer que o artefato que se observa é um ventilador, junto com o significado que se reporta a essa entidade observada - isto é, o conceito do que é um ventilador e não o significado dele ser de dado material ou cor -, é fator determinante para se saber, que o gosto do material de que esse artefato é feito não é significativo para a compreensão da mensagem veiculada por ele. Assim, sendo o significante total ou constitutivo -, ponto de partida no processo semiótico, o resultado das escolhas deste ou daquele significante, idealmente propositais, constitui um signo complexo, em que se misturam diferentes significados que almejam chegar a um intérprete com coesão. Embora existam diretrizes gerais para a compreensão do que é uma cadeira ou ventilador, ainda assim, a infinita possibilidade de variação de significantes propõe uma complexificação até dos mais simples dos artefatos, sob o ponto de vista da análise.

Partindo do significante, agora, é importante refletir sobre o que implica o estudo dos significados presentes num artefato.

\subsection{O significado}

Na teoria semiótica de Eco, principalmente em seu Tratado Geral de Semiótica [1975] (2014), o significado é por vezes apresentado como uma "unidade cultural". Mesmo que Eco não anule o uso da palavra "significado", referir-se a esse termo como unidade cultural aponta para o posicionamento do autor, no que diz respeito à valorização e à importância do contexto cultural na determinação de um significado para dado significante.

Tal abordagem implica não só o cuidado que deve ser tomado em análises semióticas, ao se requerer a consideração da cultura, a partir da qual a mensagem foi produzida e interpretada, mas, também, ela ressalta o ato humano de dar sentido ao mundo de um determinado modo. Isso implica, que todo significado que um código institui deve ser compreendido como um apresamento da realidade feito por um grupo num dado momento, marcado pela suscetibilidade às mudanças e aos enriquecimentos no decorrer do tempo. ${ }^{13}$ Assim sendo, a compreensão da dimensão semântica dos artefatos sempre deve levar em consideração essa problemática cultural, uma vez que ela pode ser responsável por criar visões muito distintas acerca do uso de um artefato. Afinal, uma cultura pode individuar diferentes talheres de mesa, cada um com seu uso específico, que outra cultura desconheça totalmente. Levando em conta a discussão sobre os artefatos, isso quer dizer que existem certas variações, ou simplesmente desconhecimento total, de significados que foram instituídos por um código. A esses significados instituídos em primeira instância, dá-se o nome de significados denotados. Considerando os artefatos, o significado

\footnotetext{
${ }^{11}$ Mas que, sem dúvidas, as escolhas realizadas por designers em seus projetos também decorrem de situações que escapam ao seu controle, como determinações da viabilidade tecnológica e de matéria-prima, bem como de atividades de outras áreas sobre um artefato já pronto, que pode direcionar o sentido da mensagem por caminhos não intencionados originalmente pelo designer.

12 Por exemplo, em vários artefatos, o gosto do material, embora passível de ser degustado, não é relevante para a leitura da mensagem.

${ }^{13}$ Para Eco "Em qualquer cultura, uma unidade cultural é simplesmente algo que aquela cultura definiu como unidade distinta, diversa de outras, podendo ser uma pessoa, uma localidade geográfica, uma coisa, um sentimento, uma esperança, uma ideia, uma alucinação." (2014, p. 56 -57)
} 
denotado, isto é, o significado que institui a compreensão daquele artefato como tal, está, por vezes, intimamente relacionado à função desempenhada ou o desígnio original dado por seu criador. ${ }^{14}$ Apontar essas questões é fundamental para melhor compreender como em certos casos, embora baseados nos significados denotados, surgem outros com muito mais força, que são os significados conotados.

Os significados conotados, por definição, sempre construídos a partir dos denotados, são igualmente dependentes do contexto cultural e das circunstâncias nas quais o artefato é produzido e interpretado. Esses significados estão profundamente relacionados a questões de valores, simbolismos e experiências prévias codificadas por uma sociedade e construídas sobre artefatos que, essencialmente em sua origem, são de uso prático. Nesse ponto, o designer nem sempre é o único agente capaz de influenciar na construção desses significados. O profissional pode, sem dúvida, agir conjuntamente com a atividade da publicidade, do marketing e, potencialmente, com toda a sociedade. ${ }^{15}$ Desse modo, para a análise dos artefatos, é fundamental notar que, por vezes, os significados conotados são tidos como mais importantes do que os denotados: na sociedade de consumo, as mais das vezes, é o aspecto simbólico dos objetos que são tidos como mais relevantes. ${ }^{16}$

Sem subestimar a importância de se identificar um significado denotado em uma cultura antes de edificar os possíveis conotados, o analista deve sempre estar atento às possíveis inversões dos significados e, igualmente, imaginar o percurso do sentido, identificando eventuais jogos de linguagem, tais como metáforas, sinédoques, metonímias, entre outros.

\section{Uma proposta de método de análise semiótica}

Considerando indispensáveis os conceitos anteriormente discutidos para a leitura do artefato como uma mensagem coerente, é preciso sistematizar o modo de como trabalhá-los, organizando um procedimento de análise em etapas.

Em certas circunstâncias, análises semióticas caminham por um percurso de observação, particularização e, por fim, generalização (JOLY, 2012; SANTAELLA, 2012). Essa sucessão de passos é bastante discutida na obra peirceana (PEIRCE, 2015; SANTAELLA, 1995), a partir das conhecidas categorias fenomenológicas (Firstness, Secondness e Thirdness), uma vez que um dos seus grandes focos é o estudo do processo de semiose.

De modo similar, o processo de análise descrito neste artigo parte da exposição do que é

\footnotetext{
${ }^{14} \mathrm{O}$ artefato em si absorve e se torna signo daquele uso que é feito dele, como disse Eco (2016, p. 198): “quando olho uma janela na fachada de uma casa, não penso, o mais das vezes, na sua função; penso num significado-janela, que se baseia na função, mas que a absorveu a ponto de esquecê-la". De modo mais sucinto, Barthes (2012, p. 53) comenta algo similar: "desde que haja sociedade, qualquer uso se converte em signo desse uso".

${ }^{15}$ No Design, comumente esse debate ocorre em torno de uma classificação de funções. A proposta feita por Löbach (2001) foi retrabalhada e aprofundada por outros autores, como por exemplo as pesquisas de Gomes Filho (2006) e Braida \& Nojima (2014a). Realizando uma abordagem diferente, mais próxima do pensamento construído neste artigo, Eco (2016) propôs uma diferenciação entre "funções primeiras" e "funções segundas", ressaltando a relação entre significados denotados e conotados em artefatos. Assim, na acepção de Eco, os termos "primeira" e/ou "segunda" não devem ser compreendidos de maneira hierárquica, mas sim como ordem de construção do pensamento e da mensagem, uma vez que os significados conotados só surgem a partir dos denotados.

${ }^{16}$ Aspecto explorado tanto por Barthes (2013), que nomeia a inversão dos significados denotados e conotados como "mito", quanto por Baudrillard (2012), que opõe a noção de mercadoria à de objeto (cultural), uma vez que o objeto de consumo é sempre signo de algo, que não simplesmente ele mesmo.
} 
observado - um artefato, passa pela determinação de contextos e circunstâncias particulares, à busca de encontrar, no particular, regras gerais (códigos) que expliquem o artefato estudado. Nesse contexto, explica-se, num primeiro momento, as etapas de análise e, posteriormente no item 5, apresenta-se a aplicação do método proposto.

\subsection{Identificação dos significantes}

O primeiro passo consiste na observação e descrição do objeto de estudo, a fim de identificar os significantes que o constituem. Isso implica uma exposição de todos os significantes que estão em contato com os sentidos do analista, além da busca por informações disponíveis sobre a constituição do artefato. Por mais óbvia ou redundante que as descrições de certas partes possam parecer, é importante um relato completo, pois nesse primeiro momento todos os significantes são considerados potencialmente relevantes para a análise.

\subsection{Delineamento do contexto e das circunstâncias}

Uma vez apontados os significantes do objeto de estudo, cabe fazer o primeiro julgamento de quais significantes são pertinentes à mensagem e quais não são. As mais das vezes, desde a descrição, certos significantes são tomados como absurdos na leitura da mensagem, já que o analista possui o código que identifica a configuração geral daquele artefato, e é capaz de identificar quais sentidos são relevantes pôr em contato com tal artefato. No entanto, existem tantos outros significantes que são tomados como importantes para a leitura da mensagem, e que podem apontar para inúmeros significados. Isso torna imperioso o conhecimento sobre a situação em que o artefato foi produzido e está inserido, isto é, a determinação da situação comunicativa, na qual o objeto de estudo está posto. Assim, nessa etapa é preciso buscar a compreensão do contexto (ou contextos) e das circunstâncias nas quais o artefato foi produzido e interpretado por um sujeito. Esta segunda etapa serve de base fundamental para a identificação e delimitação dos possíveis significados pertinentes da mensagem - logo, os níveis de denotação e conotação -, que estão sustentados por um código.

\subsection{Tentativa de reconstituição dos códigos}

A partir da compreensão do contexto e das circunstâncias de produção e de interpretação da mensagem, é possível a discussão sobre determinados códigos que podem orientar a interpretação dos significantes, para os significados que expliquem aquela mensagem, de maneira mais precisa.

A reconstituição desses códigos é feita essencialmente a partir de inferências abdutivas ${ }^{17}$ : a explicação de um dado caso (a mensagem analisada) por meio da formulação de uma hipótese sobre determinada regra existente (o código). Essa é a etapa que mais carece do repertório do analista e, logo, a que pode ser menos traduzida em uma receita procedimental. O manancial de saberes do analista, juntamente com a pesquisa que busca estendê-lo, são os maiores aliados, visto que conhecimentos das mais diversas áreas - como Sociologia, Antropologia, História, entre outras - podem ajudar na reconstituição dos códigos, mediante as restrições contextuais e circunstanciais que definem a relevância da concatenação desses saberes.

Por esse motivo, essa etapa é chamada de "tentativa", visto que uma interpretação totalmente inequívoca feita pelo analista, a partir da mensagem estudada, nem sempre é possível. Por um

\footnotetext{
${ }^{17}$ Expressão utilizada neste artigo com base na acepção peirceana (PEIRCE, 2015) de abdução.
} 
lado, é certo que em algumas situações o designer que criou o artefato em questão explicita todas as suas intenções comunicativas. Por outro, em tantas outras situações, ao analista como intérprete restam apenas suas hipóteses interpretativas, que pode comparar com outras análises já realizadas, caminhando para um possível consenso acerca do sentido da mensagem, identificando leituras válidas e/ou incomuns. ${ }^{18}$

O percurso de análise busca o desmembramento dos códigos de construção do artefato, ilustrado na figura que segue:

Figura 1 - Ilustração do procedimento de análise

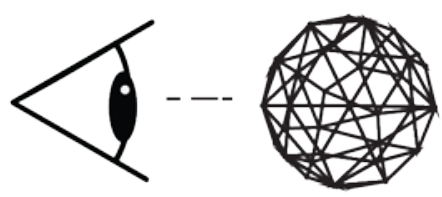

Observar e identificar os significantes

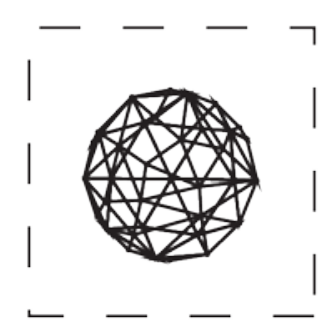

Determinação dos contextos e das circunstâncias

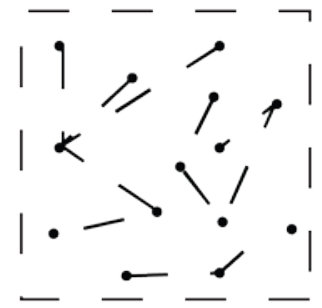

Tentativa de reconstituição dos códigos de produção

Fonte: dos autores.

Além da ilustração anterior, com o objetivo de esclarecer o que cada etapa do procedimento de análise pede, bem como os principais pontos que o analista deve estar atento ao estudar o artefato, a tabela a seguir busca uma esquematização didática:

Tabela 1 - Esquema dos procedimentos de análise.

\begin{tabular}{|c|l|l|}
\hline \multicolumn{2}{|c|}{ ETAPAS DA ANÁLISE } & \multicolumn{1}{|c|}{ Descrição } \\
\cline { 2 - 3 } Identificação dos significantes & $\begin{array}{l}\text { Descrição dos significantes que } \\
\text { podem ser observados no artefato. } \\
\text { Atenção aos significantes que são } \\
\text { considerados pertinentes à } \\
\text { mensagem. }\end{array}$ & $\begin{array}{l}\text { O material (textura, dureza entre } \\
\text { outras propriedades), formas, cores, } \\
\text { ajuste (no caso das vestimentas), } \\
\text { sons e gostos. }\end{array}$ \\
\hline
\end{tabular}

\footnotetext{
${ }^{18}$ Eis um dos problemas mais complexos da interpretação e da leitura de mensagens: a definição do que é uma interpretação cabível ou outras interpretações incomuns e disparatadas. Determinar limites para a interpretação numa dada situação comunicativa, para além do julgamento do que é bom senso, é realizar um estudo da dimensão pragmática da mensagem, uma reconstituição de suas origens e condições de interpretação, aspectos esses que devem servir de base tanto para a análise como para a argumentação, que constituirá a interpretação da mensagem de dado modo e não de outro. Nesse ponto, é importante ressaltar que todos os significantes encontrados na mensagem são tomados como intencionais: estão ali pela vontade e intento comunicativo de um designer, e não por uma relação aleatória entre suas partes.
} 


\begin{tabular}{|c|l|l|}
\hline $\begin{array}{c}\text { Delineamento dos contextos e das } \\
\text { circunstâncias }\end{array}$ & $\begin{array}{l}\text { Determinação da situação } \\
\text { comunicativa na qual o artefato está } \\
\text { inserido. Compreensão dos } \\
\text { contextos e das circunstâncias nas } \\
\text { quais o objeto de análise foi } \\
\text { produzido e interpretado. }\end{array}$ & $\begin{array}{l}\text { Designer responsável pelo projeto, } \\
\text { nome do artefato (se houver), } \\
\text { período em que foi produzido, } \\
\text { possíveis intertextualidades, } \\
\text { momento de interpretação, entre } \\
\text { outros. }\end{array}$ \\
\hline $\begin{array}{c}\text { Tentativa de reconstituição dos } \\
\text { códigos }\end{array}$ & $\begin{array}{l}\text { Inferências abdutivas a respeito dos } \\
\text { códigos que construíram a } \\
\text { mensagem. A partir da delimitação } \\
\text { proposta pela etapa anterior, } \\
\text { julgam-se os códigos mais } \\
\text { pertinentes. }\end{array}$ & $\begin{array}{l}\text { Repertório, conhecimentos } \\
\text { enciclopédicos, antropológicos, } \\
\text { sociológicos, históricos, entre } \\
\text { outros. }\end{array}$ \\
\hline
\end{tabular}

Fonte: dos autores.

Para melhor compreensão, é necessário demonstrar como esse método pode ser aplicado na análise de um artefato real. O próximo tópico deste artigo se dedica a esse objetivo.

\section{Aplicação do método: análise do artefato The Well-Tempered Chair (1986) de Ron Arad}

O artefato escolhido (Figura 2) é um bom exemplo de como nossa percepção pode ser desafiada mediante a apresentação de um significante diferente para um significado já conhecido, criando conflitos na leitura do código que enriquecem a interpretação da mensagem. Como esse artefato consegue suscitar essas questões e chamar a atenção de um observador?

Figura 2 - The Well-Tempered Chair (1986) de Ron Arad

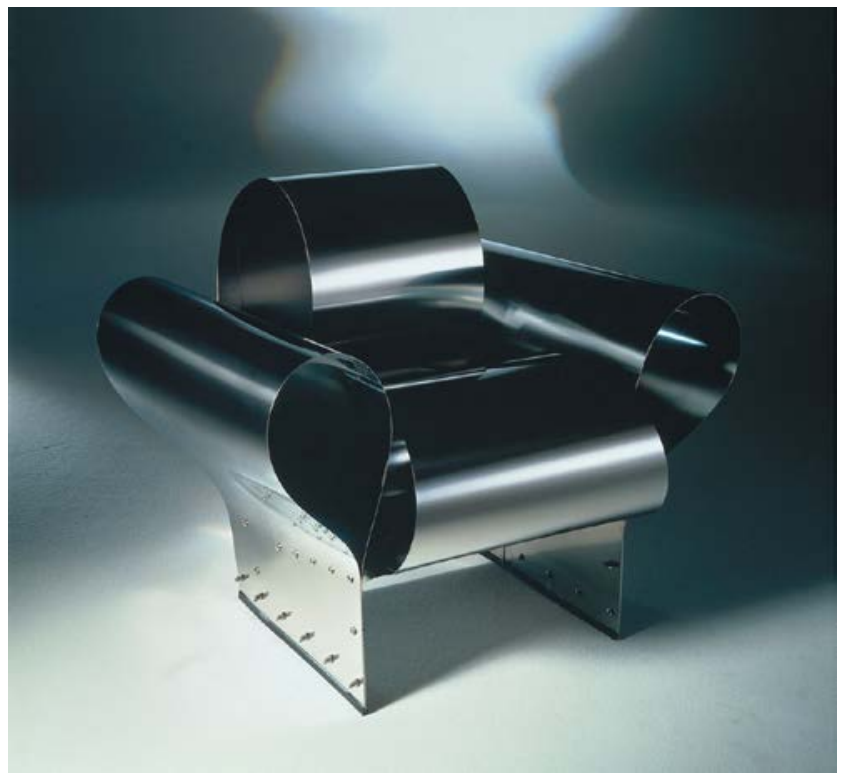

Fonte: ronarad.archivestudio.co.uk/studio-pieces/well-tempered-chair

Neste artigo, tomando em conta o objetivo de ilustrar a aplicação do método, a análise ocorreu mediante a observação de fotografias do artefato, bem como da busca por informações 
acerca do mesmo. Embora seja inegável que o potencial da análise é reduzido ao reter-se apenas ao que a imagem pode oferecer, o procedimento de análise desenvolvido não impõe qualquer restrição de aplicação a qualquer objeto físico que o analista tenha em mãos.

\subsection{Identificação dos significantes}

Uma abordagem eficaz para se realizar uma descrição completa do artefato, sem subjugar certas características como dispensáveis, é descrever o que se tem diante de si como algo nunca visto antes, caracterizando um primeiro contato. Considerando que nesse momento não se disponha de qualquer informação acerca do objeto de estudo (seu nome/título, sua função, seu criador etc.), uma descrição pura pode ser exercida. Ao observar o artefato, é notável o uso de um único material, deflagrada pela perceptível uniformidade de cor e de textura. Essa uniformidade da cor aparenta ser unicamente quebrada graças ao efeito de reflexo das luzes do ambiente, promovido pela visível superfície lisa do artefato, que aliado ao seu aspecto acinzentado, revelam o conjunto de características de um tipo de metal polido.

Além da uniformidade do material, outro aspecto que chama atenção são as formas do artefato, bem como o modo que estão dispostas. Embora com extremidades de arredondamento suave, existem partes retilíneas, como aquelas que sustentam o artefato no chão. Ao observar as formas em conjunto com a homogeneidade do material, é possível perceber que o artefato é edificado a partir de quatro lâminas de metal, que foram cuidadosamente dobradas, de tal modo, que foi possível criar um volume em quatro extremidades arredondadas. É possível observar, também, que as dobras das lâminas estão unidas por uma série de parafusos apertados com porcas visíveis, garantindo uma sensação de tensão do aço trabalhado. Graças ao resultado desse arranjo, as lâminas podem ser vistas não simplesmente como um aço dobrado, mas partes de uma forma total coerente.

Considerando que o observador virtual desse artefato já viu outras entidades da realidade, que possuem um arranjo formal parecido, ou sendo mais especifico, que conheça o que é uma cadeira ou poltrona, ele será capaz de perceber que é justamente essa entidade que o artefato é. Mesmo sendo essa uma etapa já distante do puro contato com os significantes do artefato, já que se está generalizando a ocorrência encontrada e nomeando-a "cadeira", ela ainda é uma etapa incipiente no percurso maior de leitura da mensagem.

Possuir o código que permite identificar uma cadeira, e reconhecer neste caso uma variação do significante total a que está ligado o significado "cadeira», garante o discernimento via similitude com outros casos observados, do que seriam os pés, os braços, o encosto e o assento daquele artefato, mas que não explora o significado maior propriamente dito da mensagem. Assim, a esta altura, a análise é capaz de constatar um possível significado denotado (isto é, o de cadeira designada para uso prático) para o significante total observado, mas que não assegura os intentos do designer de apresentar a cadeira daquele modo específico, nem revela significados conotados de intenção precisa. Para isso, é preciso aprofundar a pesquisa sobre a mensagem estudada, contextualizá-la.

\subsection{Delineamento do contexto e das circunstâncias}

A busca por informações sobre a situação de produção da mensagem ou quaisquer outras "pistas" sobre ela, é um movimento em direção à construção de uma interpretação mais fidedigna com aquela possivelmente desejada pelo destinador da mensagem. Essa pesquisa pode oferecer 
desde informações básicas, tais como o nome do artefato (se houver), o designer responsável e ano de criação; até conhecimentos, numa perspectiva histórica, sobre o período da história do Design em que o artefato está inserido, sobre o material e os processos de produção, se o artefato foi produzido em massa para venda ou apenas exposto, dentre outros aspectos.

No presente caso, o nome do artefato, por exemplo, mediante o conhecimento da língua inglesa, já aponta para o modo como a cadeira foi feita, levanta hipóteses consistentes sobre o material, além de suscitar a reflexão sobre um possível trocadilho. ${ }^{19}$

Um estudo sobre o designer Ron Arad e sua obra, revela a preferência do designer por trabalhos de experimentação com as possibilidades dos materiais, formas excêntricas e releituras incomuns de arquétipos de objetos ${ }^{20}$ já saturados na memória dos indivíduos. Além disso, há o fato de que muitas de suas criações já foram expostas em museus e viraram miniaturas decorativas, o que poderia reforçar a interpretação de que a função daquele artefato é muito mais reflexiva e simbólica do que prática.

No que diz respeito a uma contextualização histórica, o artefato foi projetado em meados da década de 1980, período em que abordagens funcionalistas do Design eram discutidas. Nesse debate, por exemplo, abriu-se espaço para o desenho de formas e de artefatos, que questionavam o privilégio aos conceitos e aspectos relacionados à funcionalidade, ao uso articulado à ergonomia ou à máxima a forma segue a função dos objetos. Sem pretender discutir aqui questões relacionadas à História do Design, a breve análise reforça a noção de que são significados conotados que estão prevalecendo na mensagem. Para identificá-los e poder definir um sentido geral de leitura, é preciso imaginar os códigos que constituem o artefato.

\subsection{Tentativa de reconstituição dos códigos}

Com base na discussão sobre a identificação do artefato cadeira, do seu nome, bem como do conhecimento das características dos projetos de Ron Arad, é possível levantar, que uma das interpretações na leitura da mensagem analisada é justamente um jogo de experimentação de um novo significante total, para um objeto bastante conhecido, muitas vezes concebido e produzido de outro modo.

O conhecimento do código da língua inglesa, que já aponta para a intitulação do artefato como uma cadeira, além do duplo sentido ao redor do processo metalúrgico e o equilíbrio das partes constituintes do artefato, constrói um significado conotado peculiar sobre o significado de «cadeira».

O uso do aço puro na constituição de uma cadeira dita well-tempered, considerando não o sentido dentro da metalurgia, mas o de "equilíbrio" e de "bem ajustado", que foi construída pelo processo de tempering, confronta-se com significados comumente associados ao de "cadeira", como o de "conforto». Assim, o significado "conforto», embora possa ser relacionado sem contrariedade ao sentido de "well-tempered» como "equilíbrio» (e, logo, "aprazível»), quando

\footnotetext{
${ }^{19} \mathrm{Na}$ língua inglesa, atribui-se à expressão well-tempered uma ideia de equilíbrio, de um processo ou coisa que possui moderação, ajuste e regulação sobre suas etapas ou partes (e, portanto, aprazível). No entanto, separadamente, a palavra tempered remete à forma adjetivada do substantivo tempering, processo de têmpera do aço, que, conjuntamente com o revenir, podem dar ao material resistência e elasticidade - características passíveis de observação no artefato analisado.

20 "Arquétipos de objetos" expressão utilizada por Sudjic (2010) a respeito do que se identificou neste artigo como "significante total" ou "forma total".
} 
associado ao significado de "tempering" (processo metalúrgico), este carrega associações com os significados "metal» e "dureza», que são vistos culturalmente como distantes da acepção de "conforto" para cadeiras ou poltronas. Essa contrariedade de significados, é reforçada pelo próprio estranhamento que o artefato pode causar visualmente e tacitamente: formas arredondadas que evocam comodidade ${ }^{21}$, mas que pelo tipo e uniformidade do material usado, estão ambos culturalmente e sensorialmente na ponta oposta do espectro daquilo que, habitualmente, considera-se como confortável e aconchegante. Existe aí um pequeno trabalho com a linguagem, um tipo de antonomásia tanto verbal quanto não verbal, por meio da criação de uma nova possibilidade formal para um artefato bastante conhecido, e que suscita uma série de contradições com o próprio significado culturalmente atribuído a esse significante. É possível considerar que esses contrastes foram planejados e desejados por Ron Arad, o que pode se transformar em um dos grandes cernes dessa mensagem.

Além dos significados conotados discutidos, naturalmente, há um sem número de conotações associadas muito particulares e impossíveis de listar, pois variam de acordo com a correlação do que é visto com as experiências passadas dos sujeitos que observam. Há, também, o sem fim de situações em que um indivíduo pode entrar em contato com o artefato, o que pode guiar a preferência por um dado percurso de sentido sobre outro. De todo modo, os códigos imprescindíveis para a compreensão dos significados da mensagem foram expostos e, principalmente, o modo como constroem esse significado.

Esquematizando essa análise e organizando o que foi discutido em palavras-chave dentro de uma tabela, os principais pontos da análise poderiam ser resumidos da seguinte maneira:

Tabela 2 - Resumo esquemático da análise do artefato The Well-Tempered Chair.

\section{ETAPAS DA ANÁLISE}

\section{Identificação dos significantes}

Único material, uniformidade de cor e textura.

Reflexão da luz, dando ideia de uma superfície lisa.

Aspecto acinzentado.

Aparente metal polido, como o aço.

Algumas extremidades possuem arredondamento, outras são retilíneas.

Quatro lâminas constituem o artefato.

Presença de parafusos com porcas visíveis.

Identificação da forma como de uma cadeira, embora suscite dúvida sobre sua função graças a um estranhamento

\footnotetext{
${ }^{21}$ Culturalmente evocam comodidade por estarem relacionadas ao desenvolvimento de artefatos que visam conforto, sendo assim, a compreensão de formas arredondadas, em relação ao mobiliário doméstico, como indicadores de uma qualidade atrelada ao conforto, também é parte do conhecimento de um certo código. A "cadeira" de Ron Arad, embora possua esse nome (chair), assemelha-se muito mais a uma poltrona (arm chair), artefato que, partindo do mesmo princípio e uso da cadeira, busca realizar função semelhante, mas propiciando maior descanso.
} 
Delineamento dos contextos e das circunstâncias

Nome do artefato: The Well-Tempered Chair (1986), do designer Ron Arad, 80 x $100 \mathrm{~cm}$.

Ron Arad (1951 -), designer e arquiteto, famoso pela experimentação com diferentes materiais e formas excêntricas.

Décadas de 1980-90: o boom midiático do Design, dialética entre excentricidade e simplicidade.

Intertextualidade com outros artefatos populares, como a poltrona.

Tentativa de reconstituição dos códigos

Uso do trocadilho permitido pela língua inglesa (poltrona / conforto vs. Maleabilidade do aço / dureza).

Desafio do reconhecimento de artefatos já conhecidos via abstração.

Jogo de contradições com os significados culturalmente estabelecidos para a ideia de uma cadeira confortável.

Antonomásia verbal e não verbal.

Fonte: dos autores.

\section{Conclusão}

O método de análise apresentado neste artigo buscou ressaltar a importância do conhecimento de códigos culturais para a interpretação dos significados (denotados e conotados) possíveis, que estão atrelados aos significantes (totais e constituintes) de um artefato. Esse elo entre significante e significado deve sempre ser compreendido como produto de uma cultura, suscetível às mudanças e às aglutinações ao longo do tempo, que podem variar de acordo com os contextos e as circunstâncias em que a situação comunicativa se desenvolve.

Todas as análises semióticas devem estar atentas a essas questões ao tentar reconstruir o intento original da mensagem, mediante as ressalvas impostas pelo contexto de interpretação. Trata-se de problemática mormente articulada ao Design, área que produz mensagens complexas de substâncias de expressão mistas, que muitas vezes tem seu potencial comunicacional subestimado. Quando, na verdade, o estudo da escolha de certos significantes na construção do artefato e a verificação do que possivelmente podem implicar, não são só um artifício para desvelar essa complexidade, mas também um exercício didático e enriquecedor para a própria atividade de projeto.

A análise de como as mensagens são construídas no Design, o estudo de como a linguagem do Design é utilizada para significar, são procedimentos que oferecem os meios para a reflexão sobre como projetar artefatos, que expressem melhor aquilo que seu projetista tem em mente. Por esse motivo, o método apresentado neste artigo vem sendo trabalhado em sala de aula e contribuindo para a discussão de como ocorre a produção sígnica no Design, levando à construção de um modelo esquemático de tal produção que vem sendo testado.

O domínio sobre a linguagem do Design, assim como tantas outras, não se obtém somente tentando criar mensagens a partir dos ensinamentos essenciais de uma metodologia de projeto, mas, também, a partir de um exame sobre os artefatos já construídos. Dissecar esses artefatos, identificar os acertos e os erros de um ponto de vista também comunicacional, e não só funcional ou ergonômico, é igualmente uma relevante perspectiva de estudo para a área do Design. 


\section{Referências}

BARTHES, Roland. Sistema da moda. Trad. de Ivone C. Benedetti. São Paulo: Editora WMF Martins Fontes, 2009.

Elementos de semiologia. Trad. de Izidoro Blikstein. São Paulo: Cultrix, 2012.

DIFEL, 2013.

Mitologias. Trad. de Rita Buongermino, Pedro Souza e Rejane Janowitzer. Rio de Janeiro:

BAUDRILLARD, Jean. O Sistema dos objetos. Trad. De Zulmira Ribeiro Tavares. São Paulo: Perspectiva, 2012.

BRAIDA, Frederico. A linguagem híbrida do design: um estudo sobre as manifestações contemporâneas. 2012. 297f. Tese (Doutorado em Design) - Pontifícia Universidade Católica do Rio de Janeiro, Rio de Janeiro, 2012.

BRAIDA, Frederico; NOJIMA, Vera Lúcia. Tríades do design: um olhar semiótico sobre a forma, o significado e a função. Rio de Janeiro: Rio Books, 2014a.

. Por que design é linguagem? Rio de Janeiro: Rio Books, 2014b.

BÜRDEK, Bernhard E. History, theory and practice of Product Design. Trad. de Meredith Lane, Susan Ritcher \& Nina Hausmann. Basel: Birkhäuser Verlag, 2005.

ECO, U. O signo. Trad. de Maria de Fátima Marinho. Lisboa: Editorial Presença, 1981.

. Tratado geral de semiótica. Trad. de Antônio de Pádua Danesi e Gilson Cezar de Cardoso de Souza. São Paulo: Perspectiva, 2014.

. A estrutura ausente: introdução à pesquisa semiológica. Trad. de Pérola de Carvalho. São Paulo: Perspectiva, 2016.

FARIAS, Priscila; QUEIROZ, João. Visualizando signos: modelos visuais para as classificações sígnicas de Charles S. Peirce. São Paulo: Blucher, 2017.

FERRARA, Lucrécia D’Alessio. Design em espaços. São Paulo: Edições Rosari, 2002.

GOMES FILHO, João. Design do objeto: bases conceituais. São Paulo: Escrituras Editora, 2006.

GREIMAS, A. J.; COURTÉS, J. Dicionário de semiótica. Vários tradutores. São Paulo: Contexto, 2016.

JAKOBSON, Roman. Linguística e comunicação. Trad. de Izidoro Blikstein. São Paulo: Cultrix, 2010. JOLY, Martine. Introdução à análise da imagem. Trad. de Marina Appenzeller. São Paulo: Papirus, 2012.

PEIRCE, Charles S. Semiótica. Trad. de José Teixeira Coelho Neto. São Paulo: Perspectiva, 2015.

SANTAELLA, Lucia. O que é Semiótica. São Paulo: Brasiliense, 1995.

. Semiótica aplicada. São Paulo: Cengage Learning, 2012.

SOUSA, Gustavo A. L. de. Código e artefato: uma abordagem semiótica do Design. 2017. 170f. Monografia (Bacharelado em Design) - Universidade Federal do Rio Grande do Norte, Natal, 2017.

SUDJIC, Deyan. A linguagem das coisas. Trad. de Adalgisa Campos da Silva. Rio de Janeiro: Intrínseca, 2010. 